Article

\title{
Seismic Isolation Effect of Non-Water Reacted Two-Component Polymeric Material Coating on Tunnels
}

\author{
Xue Ma ${ }^{1}$, Fuming Wang ${ }^{1,2,3,4}$, Chengchao Guo ${ }^{2,3,4, *}$ and Bo Sun ${ }^{2,3,4}$ \\ 1 School of Civil Engineering, Southwest Jiaotong University, Chengdu 610031, China; \\ xuema@my.swjtu.edu.cn (X.M.); fuming573@126.com (F.W.) \\ 2 College of Civil Engineering, Sun Yat-Sen University, Guangzhou 510275, China; sunbo0203@126.com \\ 3 Guangdong Key Laboratory of Oceanic Civil Engineering, Guangzhou 510275, China \\ 4 Guangdong Research Center for Underground Space Exploitation Technology, Guangzhou 510275, China \\ * Correspondence: guocc@zzu.edu.cn; Tel.: +86-135-237-18415
}

Received: 6 March 2020; Accepted: 2 April 2020; Published: 10 April 2020

\begin{abstract}
An isolation layer is one of the countermeasures to promote the anti-seismic performance of tunnels. A newly invented polymeric material, non-water reacted two-component polymeric material (NRTCPM), is superior in impermeability and construction efficiency. In this study, covering a tunnel with NRTCPM coating to mitigate the damage caused by an earthquake is discussed, and an Impact Resonance Test (IRT) is firstly used to obtain the damping ratios and dynamic elastic modulus of NRTCPM. By using infinite element boundary, eight dynamic numerical modelsare made to study the isolation effects based on different density, Poisson's ratio, dynamic elastic modulus and thickness of isolation layer values. Three different conditions are explored in this paper, namely (1) no NRTCPM layer coating around tunnel; (2) different densities, Poisson's ratios and dynamic elastic moduli of a polymeric layer; and (3) various thicknesses of polymeric isolation layers around the lining. Tensile and compressive stresses are compared under these different conditions. The results show that retrofitting tunnel lining with this material has a good effect on seismic isolation. An optimum density and thickness of the NRTCPM layer is suggested considering cost and strength.
\end{abstract}

Keywords: seismic isolation; polymeric coating; tunnel; infinite element

\section{Introduction}

The seismic response mitigation and seismic protection of structures have been discussed in recent decades [1-17]. For tunnels, coating with soft seismic isolation materials has been studied by many researchers. The seismic isolation effect of a rectangular-shaped tunnel was investigated by Shimamura et al. (1999). In their work, the seismic isolation layers were installed in two patterns. An isolation layer wasused around a new tunnel, or the vertical isolation walls were equipped at both sides of an existing tunnel [1]. Kim and Konagai (2000), Kim and Konagai (2001), and Konagai and Kim (2001) showed that materials with a low Poisson's ratio and a low shear modulus were preferable for enhancing the seismic efficiency of an isolation layer. They studied the influence of key material properties, such as the reduction factor $\left(\mathrm{TF}_{\text {coat }} / \mathrm{TF}_{\text {uncoat }}\right)$, on the seismic isolation effect. $\mathrm{TF}_{\text {coat }}$ and $\mathrm{TF}_{\text {uncoat }}$ are the transferring factorsin the cases with and without coating [2-4]. Takemine (2004) combined the 3D finite element method and centrifuge model to demonstrate the effectiveness of the isolation layer and cement solidification surrounding the tunnel [5]. Kiryu et al. (2012) used a polymer isolation method to reduce the seismic effect on the tunnel, and the influences of shear stiffness and thicknesses of soil covering the tunnel were studied [6]. Zhao et al. $(2013,2018)$ and Ma et al. (2018) retrofitted the tunnel with foamed concrete, andthe subsequent effectiveness of seismic isolation was evaluated by both 
numerical and experimental methods [7-9]. Xu et al. (2016) investigated the dynamic earth pressure on the tunnel via a shaking table test. They pointed out that when a geo-foam isolation layer was utilized, the earth pressure decreased to $10 \%-30 \%$ of that without a seismic isolation layer [10]. Chen et al. (2018) conducted two dynamic centrifuge tests to demonstrate the isolation effectiveness of rubber under seismic loads. The test results showed that the rubber isolation layer effectively decreased dynamic bending moments for tunnels with various diameters [11]. According to the numerical results of Roy et al. (2019), a significant reduction of axial forces and bending moments of the lining was observed when Expanded Polystyrene Geo-foam was utilized to coat the lining [12]. Furthermore, Li (2012) went through the investigations and damage features of tunnels after the Wenchuan earthquake, and he concluded that the isolation layers were able to enhance the seismic isolation performance [13].

Implementing an isolation layer is a typical passive seismic isolation method. As mentioned before, the effectiveness of seismic isolation layers using rubber, foamed concrete, asphalt-based grouting materials [14], aluminum foam [15], or polymeric materials has been verified, but these materials have some disadvantages. The strength of rubber is easily affected by changesin temperature and is weak at preventing corrosion. The strength of foam concrete is affected by freezing and thawing when water goes into the fissure of foam concrete, and it lacks the ability to provide consistent compressive strength. Asphalt-based grouting materials are sensitive to temperature [14]. Aluminum foamis prone to having slight cracks after cooling due to the characteristics of thermal expansion and cold contraction [15].

According to the work of Guo and Wang (2009), Wang et al. (2011a), Wang et al. (2011b), and Shi (2012), the non-water reacted two-component polymeric material (NRTCPM) is composed ofpolyol and polymethylene polyphenyl isocyanate. When mixed together in a specific proportion, the foamed NRTCPM is formed [18]. This material is more corrosion-resistant than rubber, and can achieve adequate strength earlier than foam concrete [18-22]. As shown in Figure 1, the tensile strength and compressive strength of NRTCPM are one order ofmagnitude, and the tensile strength has a much better performance than cement [22]. In terms of the mechanical and tribological properties, scanning electron microscope (SEM) [23] and the atomic force microscopy method (AFM) [24] have been applied to measure the mechanical and tribological properties of polymer and copoly. Gao Xiang et al. (2017) applied SEM to test NRCPM specimens with different densities. The higher the density of the specimen is, the more stable the microstructure is. Specimens with a lower density are polyhedrons, and their contact area is large [24]. Based on the mechanical properties and microstructure of NRTCPM, it has many advantages.To be specific, NRTCPM has a better waterproof performance and durability than traditional expansive polymer. It can expand rapidly (up to 10 to 20 times its initial volume) and immediately after injection, therefore saving time in the construction process. Furthermore, it does not shrink or cause additional load on the structure, and it is environmentally-friendly. The equipment for injecting NRTCPM is movable, convenient, and affordable. Li et al. (2016) studied the effectiveness of the seismic response mitigation of NRTCPM for a dam via a centrifuge test [25]; however, to the best knowledge of the authors, this material has never been utilized for the seismic isolation of tunnels.

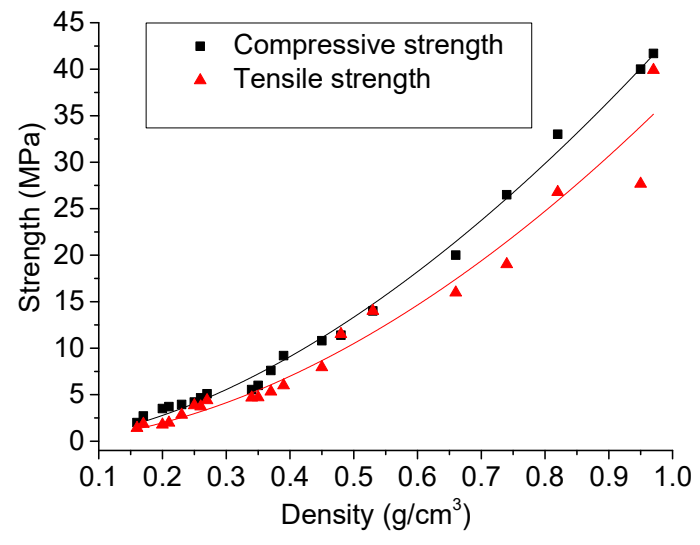

Figure 1. Density and strength. 
Within this framework, this paper aims to apply this novel NRTCPM as the isolation layer material to cover the tunnel. The compressive and tensile strength of this polymeric material is investigated, and the damping ratios and dynamic elastic moduli are obtained by an Impact Resonance Test (IRT). Furthermore, a parametric study is conducted to evaluate the influence of material properties (e.g., densities, Poisson's ratio, shear modulus, elastic modulus, etc.) on the seismic response of the lining.

\section{Dynamic Elastic Modulus from Impact Resonance Test (IRT)}

This section verifies the feasibility of using the Impact Resonance Test (IRT) to determine the dynamic elastic modulus of NRTCPM.

\subsection{Preparation of Specimens}

As shown in Figure 2a,b, the length of a seamless steel pipe is $300 \mathrm{~mm}$, and the diameter is $100 \mathrm{~mm}$. Two inner thread tube caps are separately set at the ends of the tube. A grouting head hole is drilled, and a grouting head is installed (Figure $2 \mathrm{~b}$ ). Before the mold is grouted, pipe caps from both ends are moved, and then the pipe inner wall is lubricated with silicone oil. Subsequently, two parts of the pipe are combined. After different amounts of two-component polymer are injected into the mold, various densities of specimens are produced. Finally, the $300 \mathrm{~mm}$-long cylindrical NRTCPM is cut into specimens with $100 \mathrm{~mm}$ in diameter and $50 \mathrm{~mm}$ in thickness (Figure 3).

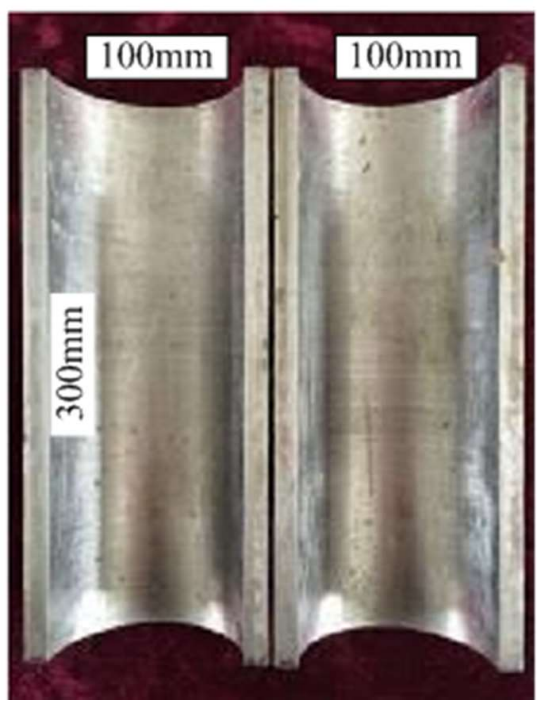

(a)

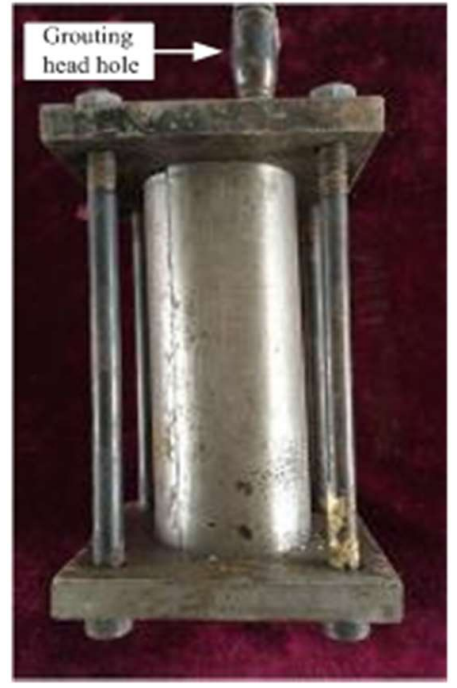

(b)

Figure 2. (a) Two halves of the mold; (b) Mold set.

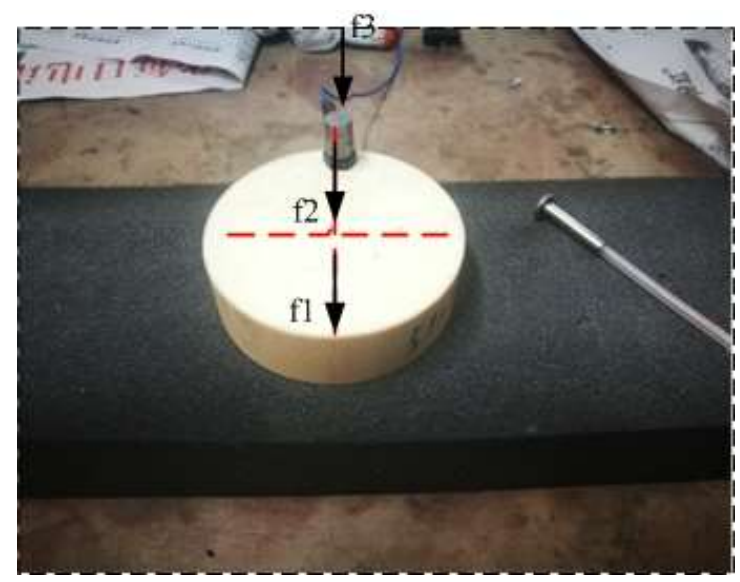

Figure 3. Specimen on the Impact Resonance Test (IRT) system. 


\subsection{Impact Resonance Test (IRT) and Theory}

The damping ratio calculations are derived from the time domain and frequency domain response of the tested material. There are various methods to estimate the level of damping, such as logarithmic decrement and half-power bandwidth methods. The half-power bandwidth methods are based on the frequency domain and were used to generate the results of damping ratios from the Impact Resonance Test (IRT) system. Traditionally, the IRT system was used to obtain a damping ratio of the asphalt mixture, and it consists of a laptop, an acceleration sensor, a signal amplifier, and a software program [26-28].

The basic concept of the test is to determine the amplitude and attenuation of vibrations and relate these parameters to the material properties. A specimen was expanded to a disc shape by injecting different amounts of NRTCPM into a mold. Figure 3 shows that the specimen with free boundary conditions is struck with a rigid impulse tool at the impact location to excite a mechanical vibration. The vibration can be received by a signal amplifier connected to the edge of the specimen (f3). As is shown in Figure 3, when the edge of the specimen is impacted (f1), a sensor, connected to the signal amplifier, captures the waveform vibrations from the short-term mechanical impact, and the first vibration mode is generated. When impacting the center of the specimen ( $\mathrm{f} 2)$, the second vibration mode can be generated. Different vibration modes correspond to different frequencies [27].

By performing a Fast Fourier Transform (FFT) algorithm, the waveform in the time domain is converted to a response in the frequency domain, as illustrated in Figure 4 [29].

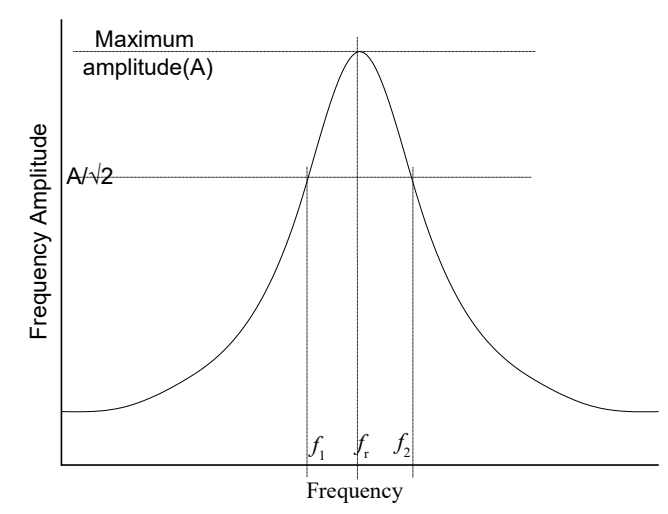

Figure 4. Damping estimation based on the half-power bandwidth method.

The frequency of the maximum amplitude is the resonant frequency $\left(f_{r}\right)$, and the $f_{1}$ and $f_{2}$ are the frequencies of the $1 / \sqrt{ } 2$ maximum amplitude in Figure 4.

The damping ratio can be obtained from $f_{r}, f_{1}$, and $f_{2}$, and it is written as:

$$
\xi=\frac{1}{2 f_{r}}\left(f_{2}-f_{1}\right) \times 100 \%
$$

$\xi$-Damping ratio

$f_{r}$-Resonant frequency

$f_{1}, f_{2}$-The frequencies of the $1 \sqrt{ } 2$ maximum amplitude.

Table 1 presents the average damping ratio of the first and second mode. When the NRTCPM's density is $0.22 \mathrm{~g} / \mathrm{cm}^{3}$, the average damping ratio is 0.04 .

Table 1. Damping ratio of specimens.

\begin{tabular}{ccc}
\hline SpecimenDensity $\left(\mathrm{g} / \mathrm{cm}^{3}\right)$ & $\begin{array}{c}\text { Average Damping Ratio } \\
\text { of the First Mode }\end{array}$ & $\begin{array}{c}\text { Average Damping Ratio } \\
\text { of the Second Mode }\end{array}$ \\
\hline 0.22 & 0.05 & 0.03 \\
\hline
\end{tabular}


The dynamic elastic modulus is an important parameter, and it can also be obtained from IRT using the following equations. The theoretical relation between the natural frequency and attenuation frequency can be written as:

$$
f_{n}=f_{d} / \sqrt{1-\xi^{2}}
$$

where,

$f_{d}$-Attenuation frequency, $\mathrm{Hz}$;

$f_{n}$-Natural frequency, $\mathrm{Hz}$;

The storage modulus $E^{\prime}$ can be calculated from the natural frequency $f_{n}$, and it can be written as [30]:

$$
E^{\prime}=\frac{4 \pi^{2} f_{n}^{2} R^{2} \rho}{\omega}
$$

where,

$E^{\prime}$-Storage modulus;

$\rho$-Density of specimen, $\mathrm{kg} / \mathrm{m}^{3}$;

$R$-Radius of specimen, $\mathrm{m}$;

$\omega$-Material parameter.

$\omega$ is related to Poisson's ratio, the thickness, and the radius ratio. The $\omega$ values of the first and second mode are presented in Tables 2 and 3. $R, \mathrm{~h}$, and $v$ are the radius, thickness, and Poisson's ratio in Tables 2 and 3.

Table 2. $₫$ value of the first mode.

\begin{tabular}{cc}
\hline $\mathbf{h} / \mathbf{R}$ & $\mathbf{1 . 0}$ \\
\hline$v=0$ & 1.101 \\
$v=0.15$ & 1.045 \\
$v=0.30$ & 0.987 \\
\hline
\end{tabular}

Table 3. $₫$ value of the second mode.

\begin{tabular}{cc}
\hline $\mathbf{h} / \mathbf{R}$ & $\mathbf{1 . 0}$ \\
\hline$v=0$ & 1.351 \\
$v=0.15$ & 1.404 \\
$v=0.30$ & 1.482 \\
\hline
\end{tabular}

The relation between the damping ratio and modulus can be expressed as follows:

$$
\xi=\tan (\varphi) / 2=\frac{E^{\prime \prime}}{2 E^{\prime}}
$$

$E^{\prime \prime}$-Loss modulus;

Therefore, the dynamic elastic modulus can be written as follows:

$$
\left|E^{*}\right|^{\prime}=\left|E^{\prime}+i E^{\prime \prime}\right|=E^{\prime} \sqrt{1+4 \xi^{2}}
$$

\subsection{Results of the IRT}

The dynamic elastic modulus can be calculated from Equation (5), and two kinds of specimens' dynamic elastic moduli are shown in Table 4. As shown in Table 4, the average dynamic elastic modulus of the first mode is $72.26 \mathrm{MPa}$, obtained from impacting the edge of specimens. The average dynamic elastic modulus of the second mode is $81.87 \mathrm{MPa}$, gained from impacting the center of specimens. 
Table 4. Results of the dynamic elastic modulus.

\begin{tabular}{cccccc}
\hline $\begin{array}{c}\text { Specimen } \\
\text { Density } \\
\left(\mathbf{g} / \mathbf{c m}^{\mathbf{3}}\right)\end{array}$ & No & $\begin{array}{c}\text { Dynamic Elastic } \\
\text { Modulus of the } \\
\text { First Mode/MPa }\end{array}$ & $\begin{array}{c}\text { Average } \\
\text { Dynamic Elastic } \\
\text { Modulus/MPa }\end{array}$ & $\begin{array}{c}\text { Dynamic Elastic } \\
\text { Modulus of the } \\
\text { Second Mode/MPa }\end{array}$ & $\begin{array}{c}\text { Average } \\
\text { Dynamic Elastic } \\
\text { Modulus/MPa }\end{array}$ \\
\hline & 1 & 69.4 & 72.26 & 73.0 & 81.87 \\
\hline & 2 & 71.0 & 91.3 & 91.3 & \\
\hline
\end{tabular}

According to the results of the dynamic elastic modulus obtained from the piezoceramic bender element done by Li [31], when the density of NRTCPM is 0.22 to $0.23 \mathrm{~g} / \mathrm{cm}^{3}$, its dynamic elastic modulus is approximately $80 \mathrm{MPa}$. The results of the dynamic elastic modulus gained by the Impact Resonance Test (IRT) are very close to the results from Li's experiment [31]. Therefore, the results of NRTCPM's dynamic elastic modulus are used in the numerical models in Section 3 below.

\section{Numerical Model}

\subsection{Infinite Element Model}

The concept of infinite elements was first presented by Ungless (1973) and Bettess (1992) [32,33]. Further constitutive work has been done by some other researchers to apply the infinite elements to the solution of static and dynamic problems in engineering practice.

The main idea in forminga static infinite element is to derive it from an element displacement shape function, and the element displacement shape function is the product of the Lagrange interpolation function (decay function). The infinite element is mapped onto a finite one by using some mapping techniques, and the mapping techniques are also employed ondynamic infinite elements. But considering the difficult mechanism of wave propagation in infinite elements, the wave propagation function in its dynamic infinite elements is replaced by the decay function in the static infinite elements [32].

Although Zhao and Valliappan. (1993), Liu et al. (2015), and Yi et al. (2019) [34-36] have successfully used the finite and infinite elements coupled method and the related wave input procedure in infinite media to solve the dynamic response, the application of this method to study the dynamic response of polymeric seismic isolation around tunnels has not been done before.

2D finite element models with infinite element boundaries are made for the nonlinear numerical analysis by ABAQUS. According to the Code for the seismic design of urban rail transit structures [37], the distance between the numerical model boundary and underground structure should be three times larger than the structure height.

The finite element (FE) model in Figure 5 is $50 \mathrm{~m}$ wide and $50 \mathrm{~m}$ deep. The diameter of the tunnel is $5.5 \mathrm{~m}$, and the thickness of the liner is $0.35 \mathrm{~m}$, as shown in Figure 5 .

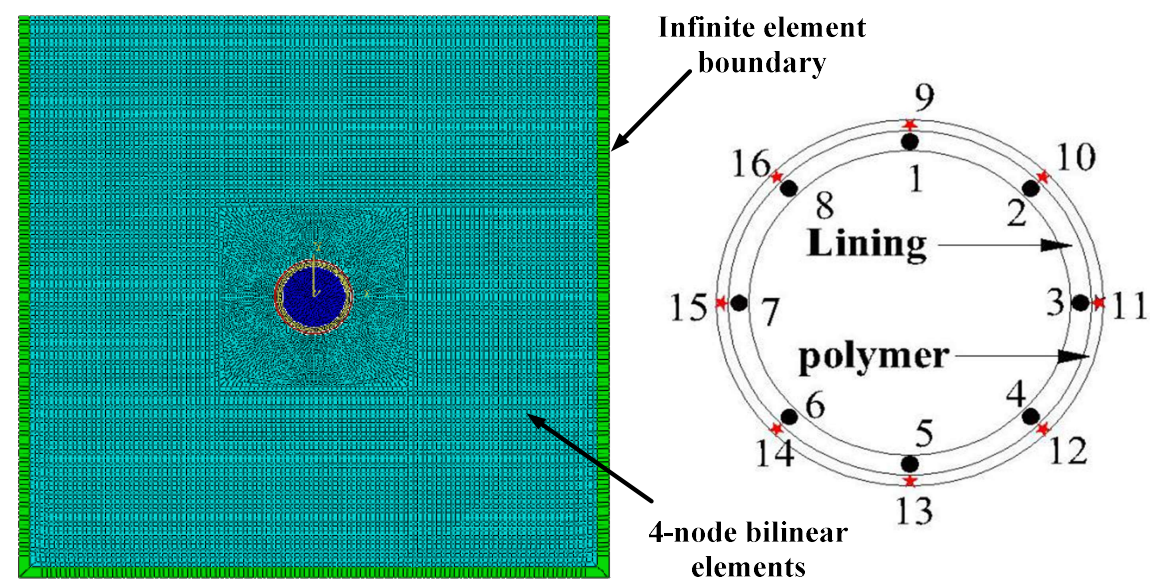

Figure 5. Geometry and mesh discretization of the numerical model (left), lining, and coating (right). 
Incompatible modes of 4-node bilinear elements are employed in the surrounding rock, lining, and polymeric material. There are 17,283 nodes and 16,941 elements with an average dimension of $0.3 \mathrm{~m}$ in the FE model. Nodal points from number 1 to number 16 on the lining and polymeric layer are shown in Figure 5. These points' stress will be analyzed in the results.

To deal with contact, a tie constraint is adopted between the surrounding soil and NRTCPM coating, and is adopted between the NRTCPM coating and the lining in order to improve the calculation of the stability and efficiency.

In the mesh center, the characteristic dimension of the elements should satisfy the condition that the spacing of the finite element nodes must be smaller than around one-eighth to one-sixth of the wavelength related to the maximum frequency component of the input motion [38].

A detail of the mesh before excavation and after equipping the NRTCPM layer and lining is shown in Figures 6 and 7.

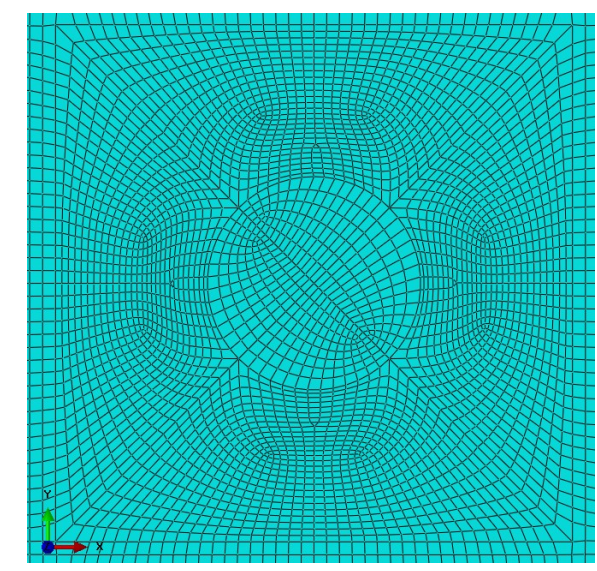

(a)

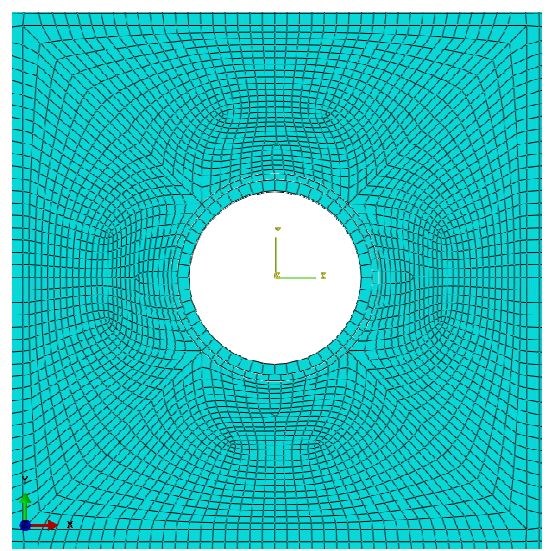

(b)

Figure 6. (a) Details of the mesh before excavation; (b) Details of the mesh after the NRTCPM and lining are retrofitted.

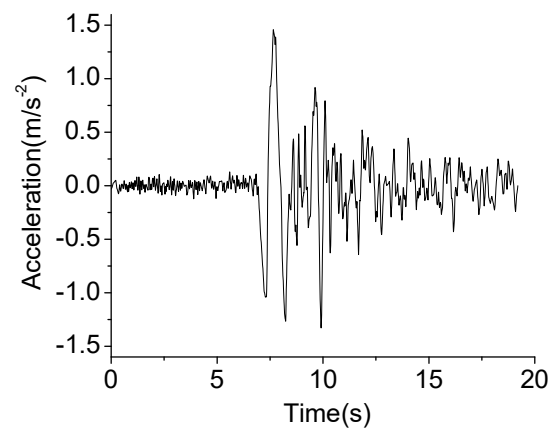

(a)

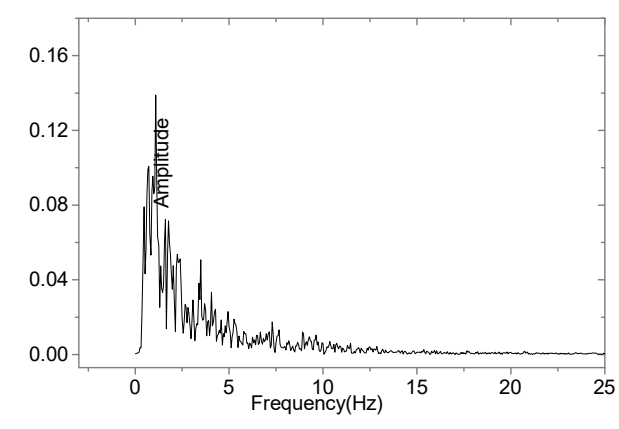

(b)

Figure 7. Horizontal time histories (a) and Fourier amplitude spectra (b).

\subsection{Material Property}

The surrounding rock is regarded as being homogeneous and isotropic, with an elastic, perfectly plastic behavior, and the Mohr-Coulomb yielding criterion is adopted in Table 5, while concrete damaged plasticity is used on the lining in Table 6. NRTCPM is evaluated using the crushable foam model. The parameters are in Table 7. 
Table 5. Parameters of the surrounding rock.

\begin{tabular}{cccccccc}
\hline Material & $\begin{array}{c}\text { Elastic } \\
\text { Modulus (GPA) }\end{array}$ & $\begin{array}{c}\text { Density } \\
\left(\mathrm{g} / \mathrm{cm}^{\mathbf{3}}\right)\end{array}$ & $\begin{array}{c}\text { Poisson's } \\
\text { Ratio }\end{array}$ & $\begin{array}{c}\text { Friction } \\
\text { Angle }\end{array}$ & $\begin{array}{c}\text { Cohesion } \\
\mathbf{( M P a})\end{array}$ & $\begin{array}{c}\text { Dilation } \\
\text { Angle }\end{array}$ & $\begin{array}{c}\text { Abs Plastic } \\
\text { Strain }\end{array}$ \\
\hline $\begin{array}{c}\text { Surrounding } \\
\text { rock }\end{array}$ & 10 & 2 & 0.25 & $35^{\circ}$ & 30 & $1^{\circ}$ & 0 \\
\hline
\end{tabular}

Table 6. Parameters of the lining.

\begin{tabular}{cccccccc}
\hline Material & $\begin{array}{c}\text { Friction } \\
\text { Angle }\end{array}$ & Eccentricity & Fb0/fc0 & K & Viscosity & $\begin{array}{c}\text { Compressive } \\
\text { Yield Stress }\end{array}$ & $\begin{array}{c}\text { Tensile Yield } \\
\text { Stress }\end{array}$ \\
\hline Lining & 36 & 0.1 & 1.16 & 0.667 & 0.00001 & $27 \mathrm{MPa}$ & $2.4 \mathrm{MPa}$ \\
\hline
\end{tabular}

Table 7. Numerical analysis cases (1 to 8).

\begin{tabular}{|c|c|c|c|c|c|c|c|c|c|}
\hline & $\begin{array}{c}\rho \\
\left(\mathrm{g} / \mathrm{cm}^{3}\right)\end{array}$ & $\begin{array}{c}\text { Initial Yield } \\
\text { Strength in } \\
\text { Uniaxial } \\
\text { Compression, } \\
\sigma c 0\end{array}$ & $\begin{array}{l}\text { Initial Yield } \\
\text { Strength in } \\
\text { Hydrostatic } \\
\text { Compression, } \\
\text { Pc0 }\end{array}$ & $\begin{array}{c}\text { Yield } \\
\text { Strength in } \\
\text { Hydrostatic } \\
\text { Tension, Pt }\end{array}$ & $\begin{array}{c}\text { Compression } \\
\text { Yield Stress } \\
\text { Ratios, k }\end{array}$ & $\begin{array}{c}\text { Hydrostatic } \\
\text { Yield Stress } \\
\text { Ratios, kt }\end{array}$ & $\begin{array}{l}\text { Yield } \\
\text { Stress }\end{array}$ & $\begin{array}{c}\text { Dynamic } \\
\text { Elastic } \\
\text { Modules } \\
\text { (MPa) }\end{array}$ & $\begin{array}{c}\text { Poisson's } \\
\text { Ratio }\end{array}$ \\
\hline 1 & 0.17 & 2.37 & 2.607 & 1.85 & 0.9 & 0.710 & 2.37 & 68 & 0.10 \\
\hline 2 & 0.22 & 2.40 & 2.640 & 1.77 & 0.9 & 0.670 & 2.40 & 77 & 0.10 \\
\hline 3 & 0.28 & 2.48 & 2.728 & 4.55 & 0.9 & 1.668 & 2.48 & 89 & 0.20 \\
\hline 6 & 0.42 & 6.92 & 7.612 & 6.98 & 0.9 & 0.916 & 6.92 & 214 & 0.23 \\
\hline 7 & 0.48 & 8.90 & 9.790 & 11.51 & 0.9 & 1.176 & 8.90 & 226 & 0.24 \\
\hline 8 & 0.54 & 10.52 & 11.572 & 14.15 & 0.9 & 1.223 & 10.52 & 228 & 0.25 \\
\hline
\end{tabular}

\subsection{Analysis Step}

The numerical simulation has been conducted by a step-by-step method; the digging operation step and the lining installation step are carried out, and the five steps are as follows:

Step one is to reproduce the initial static stress. This load creates the vertical action of the soil weight under the consideration of a coefficient at rest equal to 0.5 in both horizontal directions. Step two is named the reduce phase. The elastic modulus of the excavation area rockmass is reduced by $40 \%$. Step three is called the add phase. The lining is activated in this step. In step four, the excavation area is dug. Step five is called the dynamic phase. The seismic load is applied, and the detailed descriptions are given in Section 3.5.

\subsection{Numerical Scenarios}

Eight kinds of mechanical properties of NRTCPM are presented from Case 1 to Case 8 in Table 7 , aiming to analyze the influence of the NRTCPM layer density on the seismic isolation effect. In these cases, the thickness of the NRTCPM layer is $20 \mathrm{~cm}$. The dynamic elastic modulus and damping ratio of NRTCPM under the density of $0.22 \mathrm{~g} / \mathrm{cm}^{3}$ are from the Impact Resonance Test (IRT) done before. $\mathrm{Li}$ used the same polymeric material. Therefore, the dynamic elastic modulus of other densities can be obtained from the piezoceramic bender test done by Li et al. (2017) [31]. The tensile and compressive strength is obtained from Figure 1.

The density of the NRTCPM layer in Cases 9 to 16 is $0.22 \mathrm{~g} / \mathrm{cm}^{3}$, and these eight cases are set to research the impact of different layer thicknesses in Table 8. Case 2 and Case 12 are the same model with the same parameters and the same NRTCPM layer thickness. The numerical model without NRTCPM coating was taken as the benchmark.

Table 8. Numerical analysis cases from 9 to 16 .

\begin{tabular}{ccccccccc}
\hline Cases $\left(\mathbf{0 . 2 2} \mathbf{g} / \mathbf{c m}^{\mathbf{3}}\right)$ & $\mathbf{9}$ & $\mathbf{1 0}$ & $\mathbf{1 1}$ & $\mathbf{1 2}$ & $\mathbf{1 3}$ & $\mathbf{1 4}$ & $\mathbf{1 5}$ & $\mathbf{1 6}$ \\
\hline Thickness $(\mathrm{cm})$ & 5 & 10 & 15 & 20 & 25 & 30 & 35 & 40 \\
\hline
\end{tabular}




\subsection{Seismic Load Input}

In the dynamic simulation, the horizontal and vertical time histories (a) and their Fourier amplitude spectra (b) are shown in Figures 7 and 8, respectively. The seismic ground motion was measured at the north-south direction at the Tianjin hospital in Tangshan China in 1976, and it is a horizontal input at the boundary between finite and infinite elements on the left side of the numerical model (Figure 5). The vertical input is about four times the amplitude and acceleration of the horizontal input (Figures 7 and 8 ), and it is vertically input at the boundary between finite and infinite elements on the lower side of the numerical model (Figure 5). The duration of the analysis is $20 \mathrm{~s}$. The peak acceleration is $1.458 \mathrm{~m} / \mathrm{s}^{2}$ horizontally and $6.328 \mathrm{~m} / \mathrm{s}^{2}$ vertically. However, the acceleration of the ground motions is less than $0.5 \mathrm{~g} / \mathrm{m}^{2}$ horizontally and $2 \mathrm{~g} / \mathrm{m}^{2}$ vertically after $15 \mathrm{~s}$ and before $6 \mathrm{~s}$. The damping constants of the structure and soil are considered to be those of Rayleigh damping, namely $5 \%$.

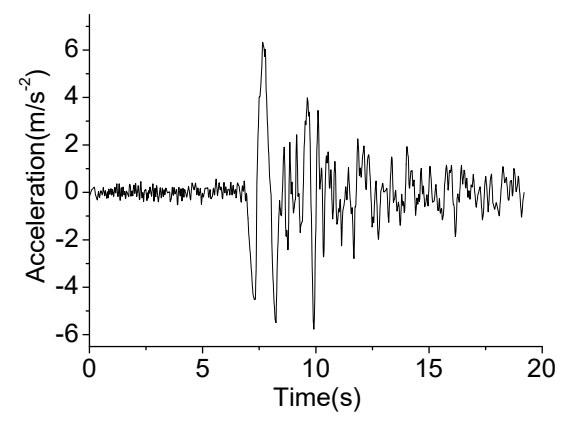

(a)

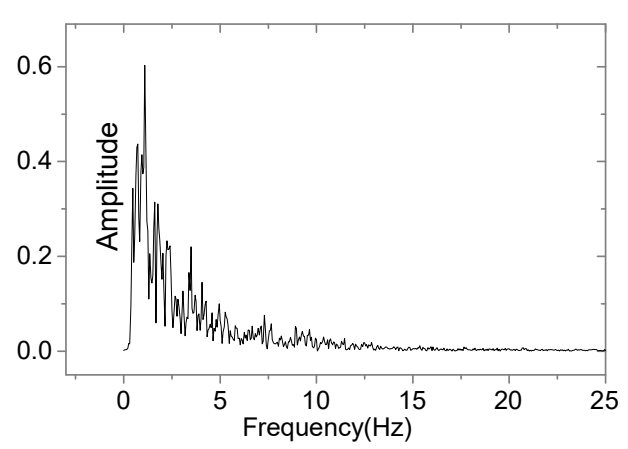

(b)

Figure 8. Vertical time histories (a) and Fourier amplitude spectra (b).

\section{Results and Discussion of Numerical Analysis}

According to the results of the finite element method, the accelerations and displacements at the same point with coating and without coating NRTCPM are very close. But the maximum principle stress varies largely. Concrete is prone to yield after tensile stress. Therefore, the isolation effect is compared here based on the maximum principle stress.

All the peak values of different points on the lining and NRTCPM coating are selected for a comparison during earthquakes. The different layer densities and dynamic elastic moduli used in the numerical model from Case 1 to Case 8 are discussed in Section 4.1, while the various thicknesses from Case 9 to Case 16 are explored in Section 4.2.

\subsection{Effect of Layer Density and Elastic Modulus(Case 1 to 8)}

The tensile stresses and absolute values of compressive stress on the lining and NRTCPM layer decrease obviously when the layer density decreases, and their variations tend to be similar, as shown in Figures 9-12.

Taking the eight points on the NRTCPM layer as an example, as the layer density decreases from $0.54 \mathrm{~g} / \mathrm{cm}^{3}$ to $0.17 \mathrm{~g} / \mathrm{cm}^{3}$, the elastic modulus decreases from $228 \mathrm{MPa}$ to $17.2 \mathrm{MPa}$ and the Poisson's ratio increases from 0.1 to 0.25 , while the compressive and tensile principal stresses go down at the same time (Figures 9 and 10). When the coating layer density decreases from $0.33 \mathrm{~g} / \mathrm{cm}^{3}$ to $0.28 \mathrm{~g} / \mathrm{cm}^{3}$ and from $0.28 \mathrm{~g} / \mathrm{cm}^{3}$ to $0.2 \mathrm{~g} / \mathrm{cm}^{3}$, the tensile stresses and absolute values of the compressive stress decrease sharply, while when the density decreases from $0.2 \mathrm{~g} / \mathrm{cm}^{3}$ to $0.17 \mathrm{~g} / \mathrm{cm}^{3}$, the tensile stresses and absolute values of the compressive stress decrease gradually. The reduction rate of the tensile stresses and absolute values of the compressive stress differs at different stages. We can see from Figure 9 that the tensile stress declines slowly at every point as the density of NRTCPM decreases from $0.54 \mathrm{~g} / \mathrm{cm}^{3}$ to $0.4 \mathrm{~g} / \mathrm{cm}^{3}$, and then rapidly within the medium density. Finally, the tensile stress at every point declines gently again. To be specific, the largest tensile stress drop value from Point No. 9 to Point 
No. 16 is $261 \mathrm{KPa}$ at Point No. 14 when the density of the NRTCPM layer decreases from $0.33 \mathrm{~g} / \mathrm{cm}^{3}$ to $0.28 \mathrm{~g} / \mathrm{cm}^{3}$, and $125 \mathrm{KPa}$ at Point No. 12 when its density decreases from $0.28 \mathrm{~g} / \mathrm{cm}^{3}$ to $0.2 \mathrm{~g} / \mathrm{cm}^{3}$, respectively. As shown in Figure 10, the compressive stress increases by $326 \mathrm{KPa}$ at Point No. 12 when the density of the NRTCPM layer decreases to $0.28 \mathrm{~g} / \mathrm{cm}^{3}$ from $0.33 \mathrm{~g} / \mathrm{cm}^{3}$, and the compressive stress goes up $127 \mathrm{KPa}$ at Point No. 15 when the density of the NRTCPM layer decreases to $0.2 \mathrm{~g} / \mathrm{cm}^{3}$ from $0.28 \mathrm{~g} / \mathrm{cm}^{3}$.

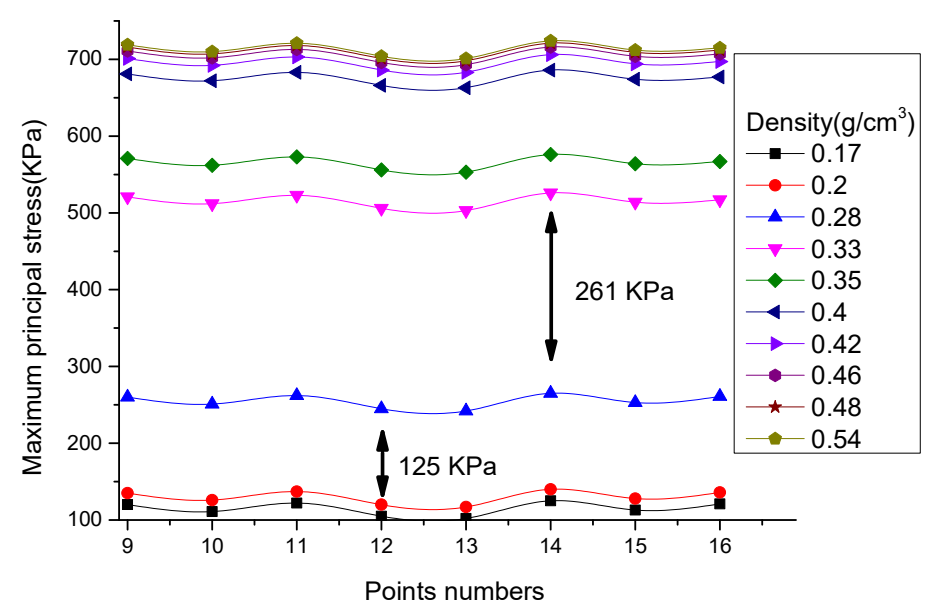

Figure 9. Tensile stress of eight points on the NRTCPM layer.

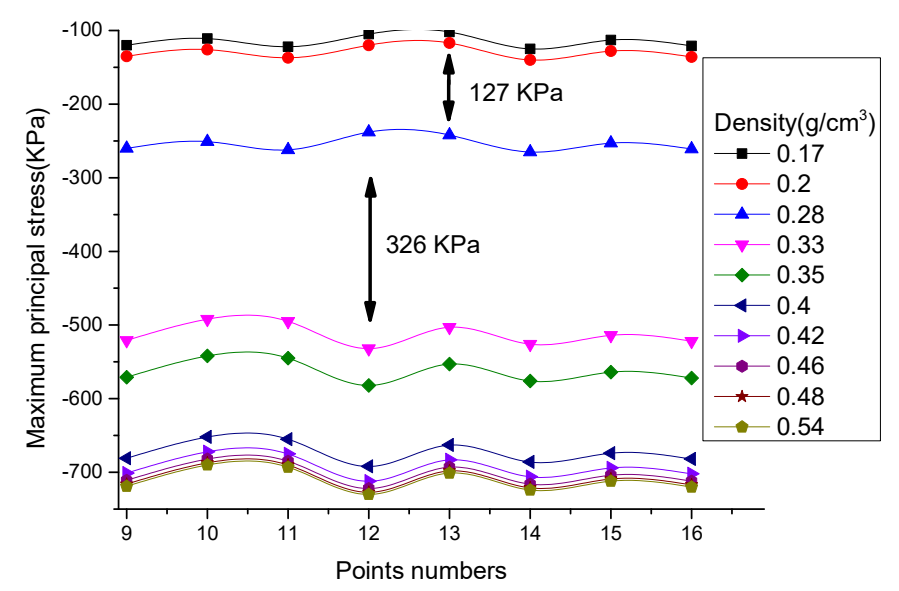

Figure 10. Compressive stress of eight points on the NRTCPM layer.

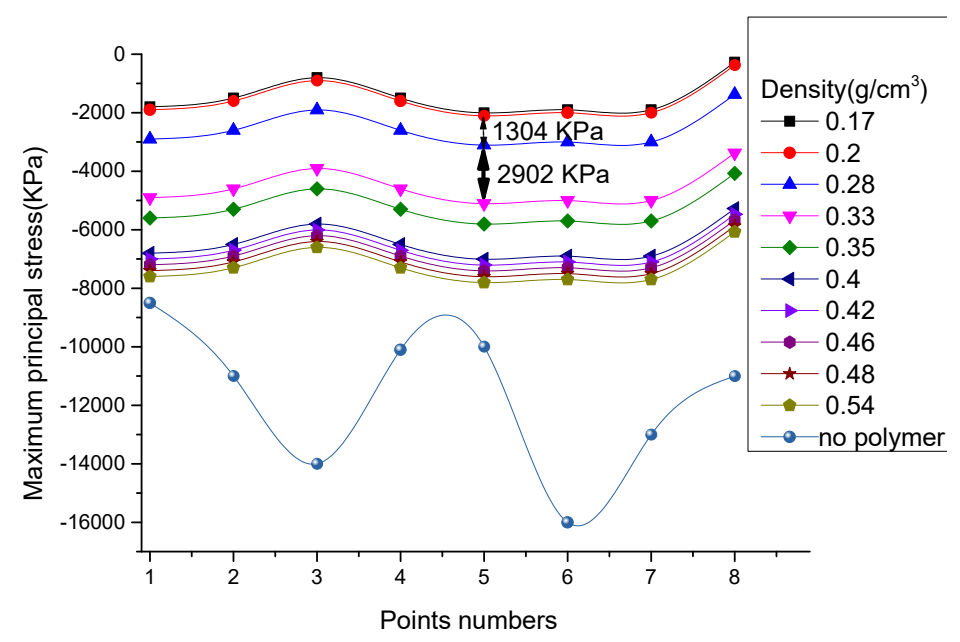

Figure 11. Compressive stress of eight points on the lining. 


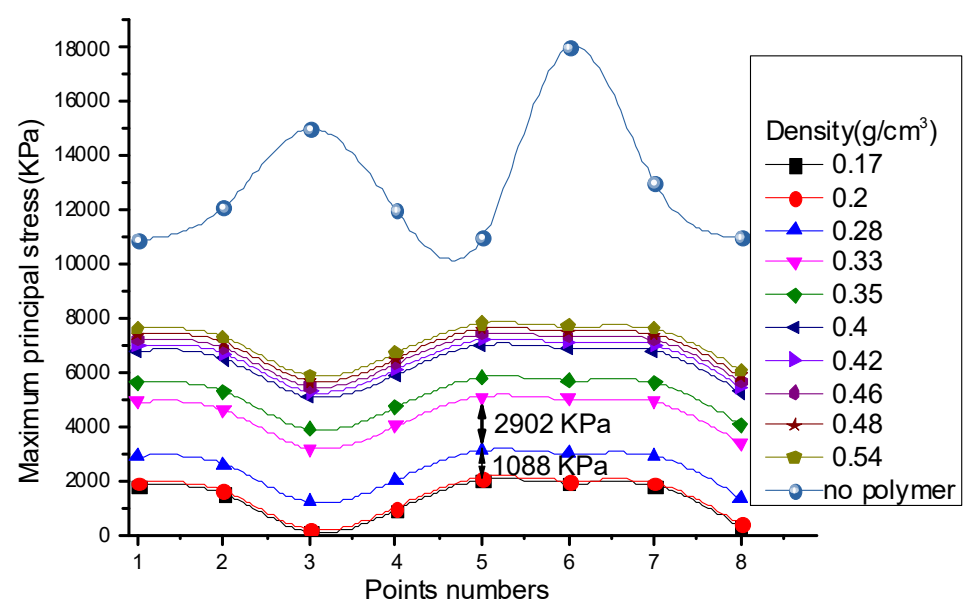

Figure 12. Tensile stress of eight points on the lining.

The changing trends of the tensile stresses and absolute values of the compressive stress on the lining shown in Figures 11 and 12 are the same as the changing trends of these stresses on the NRTCPM layer from Figures 9 and 10. When the density of the isolation layer is $0.2 \mathrm{~g} / \mathrm{cm}^{3}$, the tensile stress and absolute value of the compressive stress on the lining can be reduced by $80 \%$ on average compared with a tunnel without the condition of an isolation layer around it. It can be seen from Figure 11 that the compressive stresses increase by an average of $2902 \mathrm{KPa}$ and $1304 \mathrm{KPa}$ on all points when the density of the NRTCPM layer changes from $0.33 \mathrm{~g} / \mathrm{cm}^{3}$ to $0.28 \mathrm{~g} / \mathrm{cm}^{3}$ and from $0.28 \mathrm{~g} / \mathrm{cm}^{3}$ to $0.2 \mathrm{~g} / \mathrm{cm}^{3}$. Figure 12 shows that the tensile stress values decrease by $2902 \mathrm{KPa}$ and $1088 \mathrm{KPa}$ when the density of the NRTCPM layer changes from $0.33 \mathrm{~g} / \mathrm{cm}^{3}$ to $0.28 \mathrm{~g} / \mathrm{cm}^{3}$ and from $0.28 \mathrm{~g} / \mathrm{cm}^{3}$ to $0.2 \mathrm{~g} / \mathrm{cm}^{3}$.

In conclusion, the lower the density of the NRTCPM layer is, the more the seismic energy is taken in, and the better the seismic isolation effect performs. As the density decreases, the elastic modulus decreases too (Table 4). $0.2 \mathrm{~g} / \mathrm{cm}^{3}$ is suggested as an optimum density in view of the compressive and tensile strength reduction rate. Furthermore, the lower the density is, the lower the cost is.

\subsection{Effect of Layer Thickness(Case 9 to 16)}

As shown in Figure 13, the thicker the NRTCPM layer is, the lower the tensile stresses and absolute values of the compressive stress on the NRTCPM layer and lining are. Taking the eight points on the lining as an example, the tensile stresses and absolute values of the compressive stress on the lining decrease sharply when the isolation layer increases from a thickness of $5 \mathrm{~cm}$ to $20 \mathrm{~cm}$; however, they change slightly when the thickness of the isolation layer increases from $20 \mathrm{~cm}$ to $40 \mathrm{~cm}$ (Figures 13 and 14). We can see from Figure 13 that the drop values of the tensile stress are $2304 \mathrm{KPa}, 1024 \mathrm{KPa}$, and $588 \mathrm{KPa}$ on average for all points when the thickness of the NRTCPM layer increases from $5 \mathrm{~mm}$ to $10 \mathrm{~mm}$, from $10 \mathrm{~mm}$ to $15 \mathrm{~mm}$, and from $15 \mathrm{~mm}$ to $20 \mathrm{~mm}$, respectively. In Figure 14, the compressive stresses have a similar trend. The increased values of the compressive stress are $2313 \mathrm{KPa}$ and $1204 \mathrm{KPa}$ on average for all points when the thickness of the NRTCPM layer increases from $5 \mathrm{~mm}$ to $10 \mathrm{~mm}$ and from $10 \mathrm{~mm}$ to $15 \mathrm{~mm}$.

The absolute values of the compressive stressesand tensile stresses from number 9 to number 16 on the NRTCPM layer tend to decline in a similar trend as the points on the lining(Figures 15 and 16). According to Figure 15, the average increases in the values of the compressive stresses on eight points of the NRTCPM layer are $224 \mathrm{KPa}, 134 \mathrm{KPa}, 77 \mathrm{KPa}$, and $47 \mathrm{KPa}$, when the thickness of the NRTCPM layer increases from $5 \mathrm{~mm}$ to $10 \mathrm{~mm}$, from $10 \mathrm{~mm}$ to $15 \mathrm{~mm}$, from $15 \mathrm{~mm}$ to $20 \mathrm{~mm}$, and from $25 \mathrm{~mm}$ to $30 \mathrm{~mm}$, respectively. On the contrary, the average decrease in the values of the tensile stress on eight points on the NRTCPMlayer are $204 \mathrm{KPa}, 124 \mathrm{KPa}, 77 \mathrm{KPa}$, and $42 \mathrm{KPa}$ in Figure 16. We can conclude that a further increase of theNRTCPM layer's thickness would not have a significant effect 
on the seismic response of the lining and the seismic is olation when the NRTCPM layer's thickness reaches a certain value.

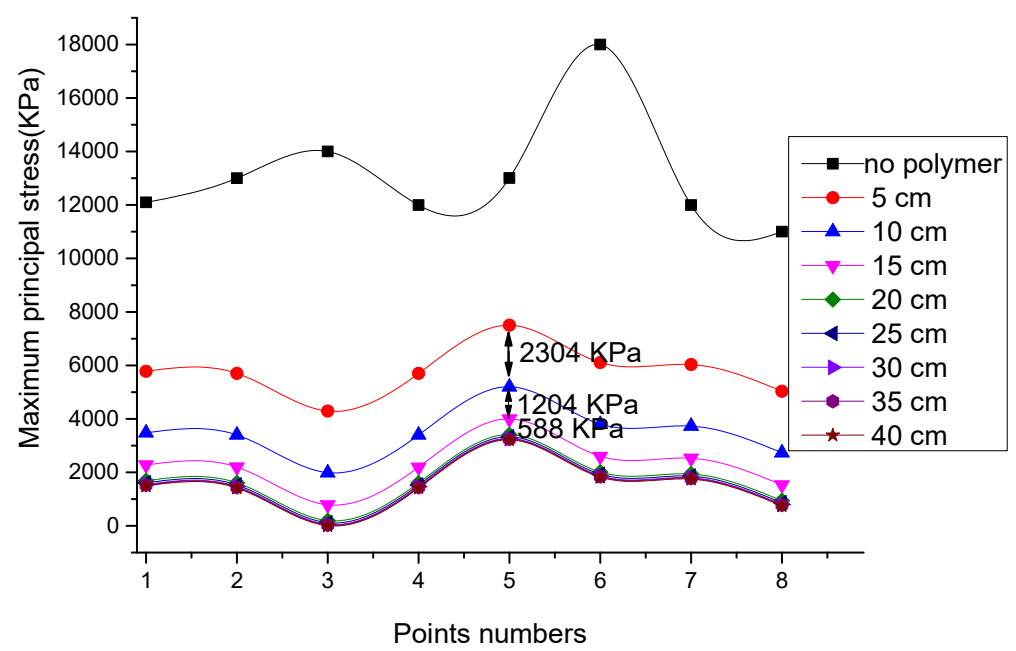

Figure 13. Tensile stress of eight points on the lining.

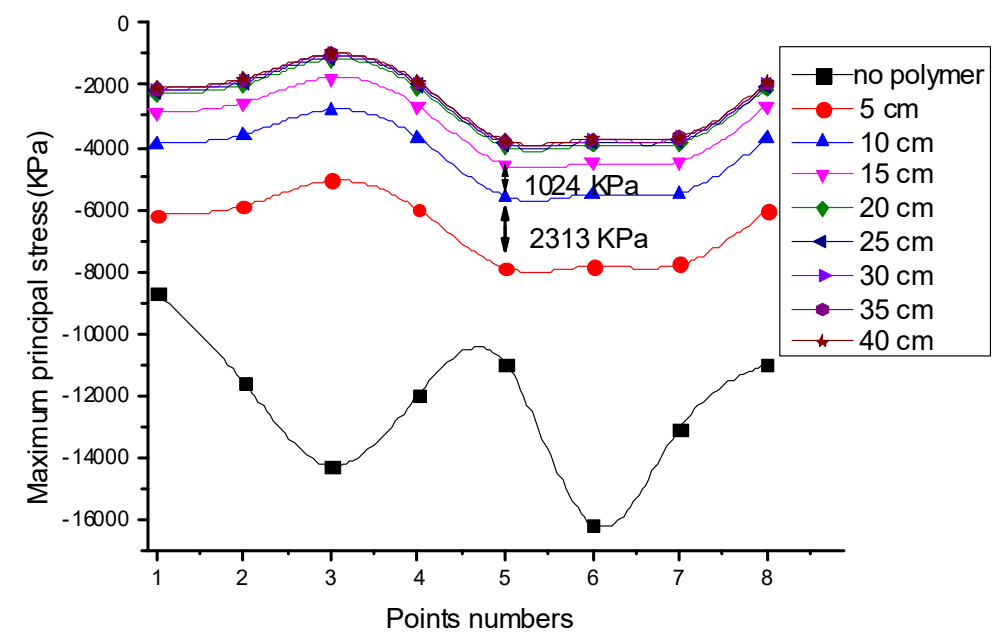

Figure 14. Compressive stress of eight points on the lining.

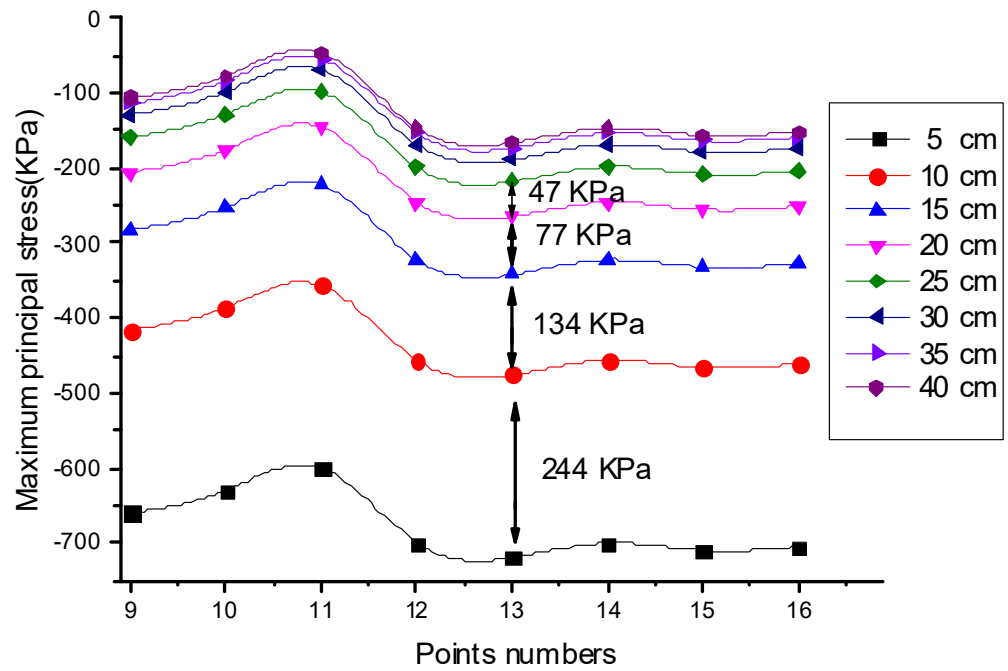

Figure 15. Compressive stress of eight points on the NRTCPM layer. 


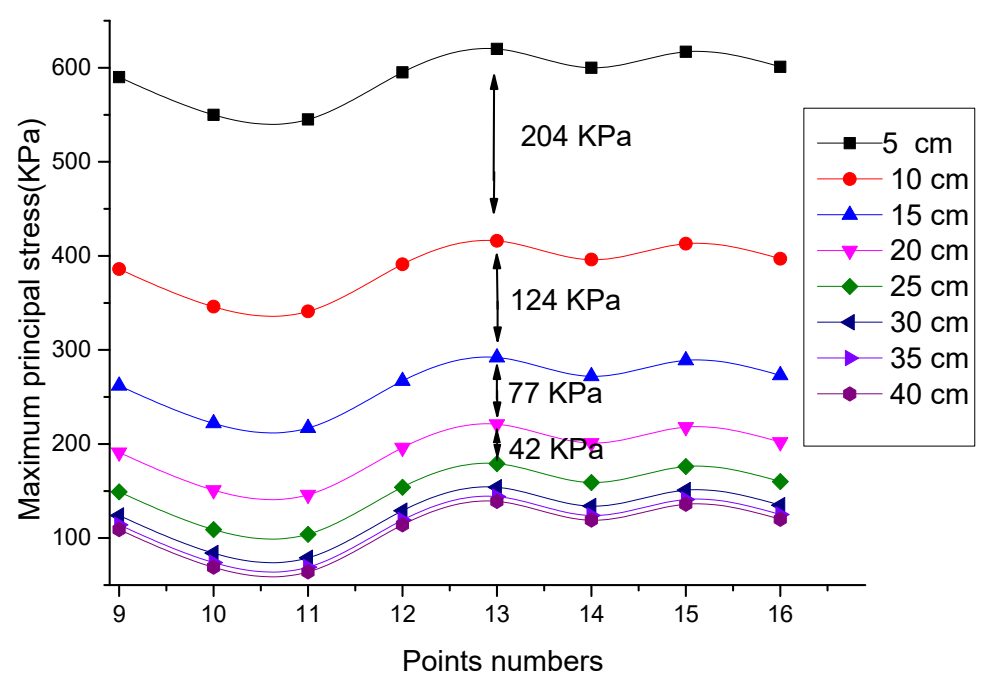

Figure 16. Tensile stress of eight points on the NRTCPM layer.

When the thickness of the isolation layer is $20 \mathrm{~cm}$, the tensile stresses and absolute values of the compressive stress can reduce $70 \%$ of stress on average compared with the condition without the NRTCPM isolation layer. Therefore, we recommend an optimum NRTCPM layer thickness of $20 \mathrm{~cm}$ considering the stress reduction rate and the construction costs of the polymeric material.

\section{Conclusions}

The main conclusions are as follows:

An impact resonance test is a reasonable and effective method to gain a damping ratio and dynamic elastic modulus of NRTCPM. When NRTCPM's density is approximately $0.2 \mathrm{~g} / \mathrm{cm}^{3}$, the average damping ratio is 0.0375 , and the average dynamic elastic modulus is $359.025 \mathrm{MPa}$ from the results of IRT. In future studies, IRT can be used to gain the damping ratios and dynamic elastic moduli of other densities' NRTCPM.

The NRTCPM is found to have good capabilities to reduce the seismic demand and attenuate the seismic load. It offers superior capabilities to protect tunnels under seismic load.

The compressive and tensile strength of NRTCPM increases as its density increases. The seismic response of NRTCPM is highly influenced by its density, elastic modulus, Poisson's ratio, and thickness. To be specific, the tensile stresses and absolute values of the compressive stress on a NRTCPM layer can be reduced by about $90 \%$ as the density decreases from $0.54 \mathrm{~g} / \mathrm{cm}^{3}$ to $0.17 \mathrm{~g} / \mathrm{cm}^{3}$ and the elastic modulus from $228 \mathrm{MPa}$ to $17.2 \mathrm{MPa}$, and the tensile stresses and absolute values of the compressive stress on the lining can be reduced by $75 \%$. When the density decreases, the elastic modulus decreases at the same time and the Poisson's ratio increases steadily. By retrofitting NRTCPM layers from $5 \mathrm{~cm}$ to $40 \mathrm{~cm}$, the tensile stresses and the absolute values of the compressive stress on the NRTCPM layer and lining can be reduced by $80 \%$ on average.

The NRTCPM layer properties, including the layer density, thickness, dynamic elastic modulus, and Poisson's ratio, are determinative factors for the seismic isolation effects of tunnels. Ultimately, the seismic isolation effect performs better at a lower density, smaller elastic modulus, and higher Poisson's ratio and thicker layer. The influences of these parameters are all significant for seismic isolation. The optimum density is $0.2 \mathrm{~g} / \mathrm{cm}^{3}$ and thickness is $20 \mathrm{~cm}$ under the consideration of cost and strength.

Author Contributions: Conceptualization, C.G. and X.M.; data curation, X.M. and B.S.; writing-original draft preparation, X.M.; writing-review and editing, C.G. and X.M.; funding acquisition, C.G. and F.W. All authors have read and agreed to the published version of the manuscript. 
Funding: This research was funded by University-Study-Research Cooperation Program of Henan Province, grant number (172107000032); Key Research-development and Transformation Project of Tibet Autonomous Region, grant number (XZ201801-GB-07)

Conflicts of Interest: The authors declare no conflict of interest.

\section{References}

1. Shimamura, S.; Kasai, H.; Haruumi, M. Seismic isolation effect for a tunnel with a soft isolation layer. Struct. Eng. Earthq. Eng. 1999, 16, 143-154. [CrossRef]

2. Kim, D.S.; Konagai, K. Seismic isolation effect of a tunnel covered with coating material. Tunn. Underg. Space Technol. 2000, 15, 437-443. [CrossRef]

3. Kim, D.S.; Konagai, K. Key parameters governing the performance of soft tunnel coating for seismic isolation. Earthq. Eng. Struct. Dyn. 2001, 30, 1333-1343. [CrossRef]

4. Konagai, K.; Kim, D.-S. Simple evaluation of the effect of seismic isolation by covering a tunnel with a thin flexible material. Soil Dyn. Earthq. Eng. 2001, 21, 287-295. [CrossRef]

5. Yamada, H.; Nagatani, H.; Ohbo, N. Seismic performance of flat cross sectional tunnel with countermeasures. In Proceedings of the13th World Conference on Earthquake Engineering, Vancouver, BC, Canada, 1-6 August 2004; p. 706.

6. Kiryu, S.; Murono, Y.; Morikawa, H. Seismic response of a cut-and-cover tunnel isolated by polymer material. Earthq. Eng. Struct. Dyn. 2001, 41, 2043-2057. [CrossRef]

7. Zhao, W.; Chen, W.; Tan, X.; Huang, S. High-performance foam concrete for seismic-isolation materials of tunnels. Chin. J. Geotech. Eng. 2013, 35, 1544-1552.

8. Zhao, W.; Chen, W.; Ma, S.; Zhao, K. Isolation effect of foamed concrete layer on the seismic responses of tunnel. Rock Soil Mech. 2018, 39, 1027-1036. [CrossRef]

9. Ma, S.; Chen, W.; Zhao, W. Mechanical properties and associated seismic isolation effects of foamed concrete layer in rock tunnel. J. Rock Mech. Geotech. Eng. 2018, 1-13. [CrossRef]

10. Xu, H.; Li, T.; Xia, L.; Zhao, J.X. Shaking table tests on seismic measures of a model mountain tunnel. Tunn. Underg. Space Technol. 2016, 60, 197-209. [CrossRef]

11. Chen, Z.; Liang, S.; Shen, H.; He, C. Dynamic centrifuge tests on effects of isolation layer and cross-sectiondimensions on shield tunnels. Soil Dyn. Earthq. Eng. 2018, 109, 173-187. [CrossRef]

12. Roy, N.; Bharti, S.D.; Kumar, A. Seismic isolation oftunnels inblocky rock mass using expandedpolystyrene (EPS) Geofoam. Innov. Infrastruct. Solut. 2019, 4, 38. [CrossRef]

13. $\mathrm{Li}, \mathrm{T}$. Damage to mountain tunnels related to the Wenchuan earthquake and some suggestions for seismic tunnel construction. B Eng. Geol. Environ. 2012, 71, 297-308. [CrossRef]

14. Zhao, B. Research on Seismic Isolation Performance of Bituminous Backfill Grouting Material for Shield Tunnel. Master's Thesis, Southwest Jiaotong University, Chengdu, China, 2019.

15. Su, L.; Liu, H.; Yao, G.; Zhang, J. Experimental study on the closed-cell aluminum foam shock absorption layer of a high-speed railway tunnel. Soil Dyn. Earthq. Eng. 2019, 119, 331-345. [CrossRef]

16. Stanikzai, M.H.; Elias, S.; Rupakhety, R. Seismic Response Mitigation of Base-Isolated Buildings. Appl. Sci. 2020, 10, 1230. [CrossRef]

17. González-Sanz, G.; Escolano-Margarit, D.; Benavent-Climent, A. A New Stainless-Steel Tube-in-Tube Damper for Seismic Protection of Structures. Appl. Sci. 2020, 10, 1410. [CrossRef]

18. Chengchao, G.; Fuming, W.; Chengchao, G. Mechanism study on the construction of ultra-thin antiseepage wall by polymer injection. J. Mater. Civ. Eng. 2012, 24, 1183-1192. [CrossRef]

19. Guo, C.; Wang, F. Research on Polymer Injection Technology for Quick Tunnel Repairment. In Proceedings of the Geohunan International Conference, Hunan, China, 3-6 August 2009.

20. Wang, F.; Wang, J.; Shi, M.; Guo, C.; Zhong, Y.; Zhang, B. Directional Fracture Grouting Method with Polymer for Seepage Control of Dikes and Dams. U.S. Patent 8,182,178 B2, 22 May 2012.

21. Wang, F.; Wang, J.; Shi, M.; Liu, W.; Guo, C.; Li, Q. Process for Grouting a Curtain. U.S. Patent 20,110,103,899A1, 5 May 2011.

22. Shi, M. Research on Polymer Grouting Material Property and Directional Fracturing Grouting Mechanism for Dikes and Dams. Ph.D. Thesis, Dalian University of Technology, Dalian, China, 2012. 
23. Gao, X.; Huang, W.; Wei, Y.; Zhong, Y. Experiment and modeling for compressive strength of polyurethane grout materials. Fuhe Cailiao Xuebao Acta Mater. Compos. Sin. 2017, 34, 438-445. [CrossRef]

24. Kuznetsova, T.A.; Zubar, T.I.; Lapitskaya, V.A.; Sudzilouskaya, K.A.; Chizhik, S.A.; Didenko, A.L.; Svetlichnyi, V.M.; Vylegzhanina, M.E.; Kudryavtsev, V.V.; Sukhanova, T.E. Tribological properties investigation of the thermoplastic elastomers surface with the AFM lateral forces mode. IOP Conf. Series Mater Sci. Eng. 2017, 256, 012022. [CrossRef]

25. Li, J.; Wang, B.; Zhang, J. Dynamic centrifuge test on seismic acceleration response of earth dike and dam with polymer anti-seepage wall. Earthq. Eng. Eng. Dyn. 2016, 36, 1-6. (In Chinese)

26. Fu, X. Experimental Research on Dynamic Modulus of Asphalt MixtureBased on Unconstrained Resonant Test. Master's Thesis, Harbin Institute of Technology, Harbin, China, 2015.

27. Zhang, L.; Li, T.-S.; Tan, Y.-Q. The potential of using impact resonance test method evaluating the anti-freeze-thaw performance of asphalt mixture. Constr. Build. Mater. 2016, 115, 54-61. [CrossRef]

28. Boz, I.; Bekiroglu, K.; Solaimanian, M.; Lagoa, P. Validation of Model Order Assumption and Noise Reduction Method for the Impact Resonance Testing of Asphalt Concrete. J. Nondestruct.Eval. 2017, 36, 1-13. [CrossRef]

29. Boz, I.; Solaimanian, M. The Impact of Specimen Size and Void Content on the Impact Resonance Testing of Asphalt Concrete. In Proceedings of the 93rd Annual Meeting of the Transportation Research Board and Potential Publication in the Transportation Research Record, Washington, DC, USA, 12-16 January 2014.

30. Martincek, G. The determination of poisson's ratio and the dynamic modulusof elasticity from the frequencies of natural vibration in thick circular plates. J. Sound Vib. 1965, 2, 116-127. [CrossRef]

31. Li, J.; Wang, B.; Zhang, J.; Hu, H. Experimental research on dynamic property of polymer grouting materials. J. Build. Mater. 2017, 20, 198-203. (In Chinese)

32. Ungless, R.F. An Infinite Finite Element. Ph.D. Thesis, University of British Columbia, Vancouver, BC, Canada, 1973.

33. Bettess, P. Infinite Element; Penshaw Press: Sunderland, UK, 1992.

34. Zhao, C.; Valliappan, S. Dynamic analysis of a reinforced retaining wall using finite and infinite elements coupled methods. Comput. Struct. 1993, 47, 239-244. [CrossRef]

35. Liu, P.; Wang, D.; Oeser, M. Application of semi-analytical finite element method coupled with infinite element for analysis of asphalt pavement structural response. J. Traffic Transp. Eng. 2015, 2, 48-58. [CrossRef]

36. Yi, H.; Qi, T.; Qian, W.; Lei, B.; Pu, B.; Yu, Y. Influence of long-term dynamic load induced by high-speed trains on the accumulative deformation of shallow buried tunnel linings. Tunn. Underg. Space Technol. 2019, 84, 166-176. [CrossRef]

37. GB 50909-2014. Code for seismic design of urban rail transit structures. In Ministry of Housing and Urban-rural Development of the People's Republic of China(MOHURD); China Jihua Press: Beijing, China, 2014.

38. Amorosi, A.; Boldini, D.; Falcone, G. Numerical prediction of tunnel performance during centrifuge dynamic tests. Acta Geotech. 2014, 9, 581-596. [CrossRef]

(C) 2020 by the authors. Licensee MDPI, Basel, Switzerland. This article is an open access article distributed under the terms and conditions of the Creative Commons Attribution (CC BY) license (http://creativecommons.org/licenses/by/4.0/). 